\title{
Influence of Chemically Modified Ultra-High Molecular Weight Polyethylene on the Properties of Butadiene Nitrile Rubber
}

\author{
Nikolay V. Shadrinov, \\ Vladimir D. Gogolev and Tatyana A. Isakova* \\ Institute of Oil and Gas Problems of the SB RAS \\ Yakutsk, Russian Federation
}

Received 02.04.2021, received in revised form 12.05.2021, accepted 21.06.2021

\begin{abstract}
For the manufacture of frost-resistant oil and petrol-resistant rubber products, one of the most widely used rubbers is nitrile-butadiene rubber (NBR) with a low acrylonitrile content of 17-20\%. However, the technical properties of its vulcanizates do not always meet all high performance requirements. Therefore, the study of the possibility of improving the technical characteristics of vulcanizates based on frost-resistant NBR is an urgent task. This paper presents the results of studying nitrile-butadiene rubber BNKS-18AMN filled with ultra-high molecular weight polyethylene (UHMWPE). A feature of this work is the study of the possibility of increasing the technical properties of the obtained elastomeric composites by increasing the interaction between chemically inert UHMWPE and BNKS-18AMN using the chemical modification of UHMWPE. The modification of UHMWPE was carried out by chemical etching in a solution of chromic acid for 3 and 20 hours. A complex of laboratory studies of the obtained samples was carried out. The influence of the duration of chemical etching of UHMWPE on the rheological and vulcanization properties has been studied on the analyzer of the processing of rubber. It is shown that the filling of UHMWPE into BNKS-18AMN, in general, leads to an increase in the viscosity of the rubber compound. Chemical etching of UHMWPE leads to a decrease in the rate of vulcanization and the density of the three-dimensional spatial structure of the vulcanizate. The study of the physical and mechanical properties in tension, wear resistance during abrasion and swelling in standard hydrocarbon liquid for testing rubbers SZR-3 showed that chemical etching of UHMWPE leads to a decrease in strength characteristics, but at the same time leads to an increase in resistance to abrasion and has no significant effect on swelling. The study of changes in the properties of samples after heat exposure showed that chemical etching of UHMWPE significantly reduces the resistance to thermal oxidative destruction in the presence of atmospheric oxygen, but does not affect the resistance to thermal aging in the SZR-3 hydrocarbon environment.
\end{abstract}

Keywords: ultra-high molecular weight polyethylene, chemical etching, chromic acid, butadiene-nitrile rubber, physical and mechanical properties, wear resistance, heat aging.

Citation: Shadrinov N.V., Gogolev V.D., Isakova T. A. Influence of chemically modified ultra-high molecular weight polyethylene on the properties of butadiene nitrile rubber, J. Sib. Fed. Univ. Eng. \& Technol., 2021, 14(4), 424-432. DOI: 10.17516/1999494X-0323

(C) Siberian Federal University. All rights reserved

This work is licensed under a Creative Commons Attribution-Non Commercial 4.0 International License (CC BY-NC 4.0).

* Corresponding author E-mail address: tanchik1985@mail.ru 


\title{
Влияние химически модифицированного \\ сверхвысокомолекулярного полиэтилена \\ на свойства бутадиен-нитрильного каучука
}

\author{
Н. В. Шадринов, В. Д. Гоголев, Т. А. Исакова \\ Институт проблем нефти и газа СО РАН \\ Российская Федерация, Якутск
}

\begin{abstract}
Аннотация. Для изготовления морозостойких маслобензостойких резинотехнических изделий одним из наиболее широко применяемых каучуков является бутадиен-нитрильный каучук (БНК) с низким содержанием акрилонитрила 17-20\%. Однако технические свойства его вулканизатов не всегда удовлетворяют всем высоким эксплуатационным требованиям. Поэтому исследование возможности улучшения технических характеристик вулканизатов на основе морозостойкого БНК является актуальной задачей. В данной работе представлены результаты исследования бутадиен-нитрильной резины БНКС-18АМН, наполненной сверхвысокомолекулярным полиэтиленом (СВМПЭ). Особенностью работы является изучение возможности увеличения технических свойств получаемых эластомерных композитов за счет повышения взаимодействия между химически инертным СВМПЭ и БНКС-18АМН с помощью химической модификации СВМПЭ. Модификация СВМПЭ проведена путем химического травления в растворе хромовой кислоты в течение 3 и 20 ч. Проведен комплекс лабораторных исследований полученных образцов. На анализаторе перерабатываемости резин исследовано влияние продолжительности химического травления СВМПЭ на реологические и вулканизационные свойства. Показано, что введение СВМПЭ в БНКС-18АМН в целом приводит к увеличению вязкости резиновой смеси, а химическое травление СВМПЭ - к уменьшению скорости протекания вулканизации и плотности трехмерной пространственной структуры вулканизата. Исследование физико-механических свойств при растяжении, износостойкости, при абразивном истирании и набухании в стандартной углеводородной жидкости для испытания резин СЖР-3 показало, что химическое травление СВМПЭ вызывает уменьшение прочностных показателей, но в то же время повышает стойкость к абразивному истиранию и не имеет существенного влияния на набухание. Исследование изменения свойств образцов после теплового воздействия показало, что химическое травление СВМПЭ существенно снижает стойкость к термоокислительной деструкции в условиях доступа кислорода воздуха, но не влияет на стойкость к тепловому старению в углеводородной среде СЖР-3.
\end{abstract}

Ключевые слова: сверхвысокомолекулярный полиэтилен, химическое травление, хромовая кислота, бутадиен-нитрильный каучук, физико-механические свойства, износостойкость, тепловое старение.

Цитирование: Шадринов, Н. В. Влияние химически модифицированного сверхвысокомолекулярного полиэтилена на свойства бутадиен-нитрильного каучука / Н. В. Шадринов, В. Д. Гоголев, Т. А. Исакова // Журн. Сиб. федер. ун-та. Техника и технологии, 2021, 14(4). С. 424-432. DOI: 10.17516/1999-494X-0323

\section{Введение}

В настоящее время для изготовления маслобензостойких резинотехнических изделий (РТИ) одним из наиболее широко применяемых каучуков признан бутадиен-нитрильный каучук (БНК), который является продуктом сополимеризации бутадиена с акрилонитрилом (НАК). Свойства сополимера зависят от содержания НАК [1, 2], чем выше содержание нитрила в полимере, тем выше его устойчивость к действию масел и алифатических углеводородов,

$$
-425-
$$


но ниже упруго-прочностные характеристики и морозостойкость. Поэтому зачастую технические характеристики резин на основе морозостойкого БНК с содержанием акрилонитрила 17-20 \% не всегда удовлетворяют всем высоким требованиям, которые предъявляются к РТИ, применяющихся в узлах техники, эксплуатируемой в климатических условиях Севера.

Изучению возможности повышения тех или иных свойств морозостойкого БНК с помощью различных способов объемной и поверхностной, физической и химической модификации посвящено множество работ. Наиболее часто встречаемые работы по объемной модификации морозостойкого БНК связаны с исследованием влияния углеродных [3, 4], волокнистых [5] и других [6] наполнителей и пластификаторов $[7,8]$ на его агрессивостойкость, морозостойкость, физико-механические и структурные свойства.

Вследствие наличия ненасыщенных двойных связей в молекуле БНК подвержен протеканию термоокислительных процессов, приводящих к потере эксплуатационных свойств РТИ, изготовленных на его основе. Одним из эффективных способов повышения стойкости БНК к термодеструкции является смешение с насыщенными полимерами [9-11]. При создании такого рода смесевых композиций важным фактором для достижения высоких упругопрочностных и других механических свойств выступает совместимость смешиваемых полимеров. Плохая межфазная адгезия между полимерными матрицами может стать причиной низких свойств таких композитов.

В представленной работе для повышения взаимодействия между морозостойким БНК с содержанием акрилонитрила 17-23 \% и сверхвысокомолекулярным полиэтиленом (СВМПЭ) [12-14] рассмотрен способ химического травления поверхности СВМПЭ. В частности, исследовано влияние химически модифицированного СВМПЭ на комплекс свойств резины на основе БНК.

\section{Экспериментальная часть}

В качестве бутадиен-нитрильного каучука использован БНКС-18АМН с содержанием акрилонитрильной группы 17-23 \% производства ОАО «Красноярский завод СК» (ТУ 38.30313 2006), в качестве СВМПЭ - GUR-4113 с молекулярной массой 3,9x106 г/моль производства Ticona (Германия). Образцы для исследования изготовлены на основе стандартной резиновой смеси, включающей 100 мас. ч. БНКС-18АМН, 5-15 мас. ч. СВМПЭ, 50 мас. ч. технического углерода марки П803, 2,5 мас. ч. оксида цинка, 1,5 мас. ч. стеариновой кислоты, 2,5 мас. ч. серы и 1,5 мас. ч. альтакса.

Химическое травление поверхности СВМПЭ проведено в растворе хромовой смеси, приготовленном смешением $\mathrm{K}_{2} \mathrm{Cr}_{2} \mathrm{O}_{7}, \mathrm{H}_{2} \mathrm{SO}_{4}$ и $\mathrm{H}_{2} \mathrm{O}$ в соотношении 7:150:12 соответственно $[15,16]$. Для этого СВМПЭ помещен в травильный раствор при комнатной температуре в течение 3 и 20 ч. После травления СВМПЭ промывали сначала проточной дистиллированной водой в течение 2 мин, а потом этанолом в течение 2 мин. Затем травленый СВМПЭ профильтрован и просушен в вакуумной печи при комнатной температуре в течение 12 ч. При этом реакция поверхностного окисления порошка СВМПЭ раствором дихромата калия может протекать по следующей схеме (рис. 1).

Смешение резиновой смеси произведено на лабораторных вальцах См350 150/150 (Китай) в течение 30 мин. Образцы для исследований вулканизованы в гидравлическом прессе 100-400 $2 \ni$ (Россия) при температуре $155{ }^{\circ} \mathrm{C}$ в течение 20 мин. 


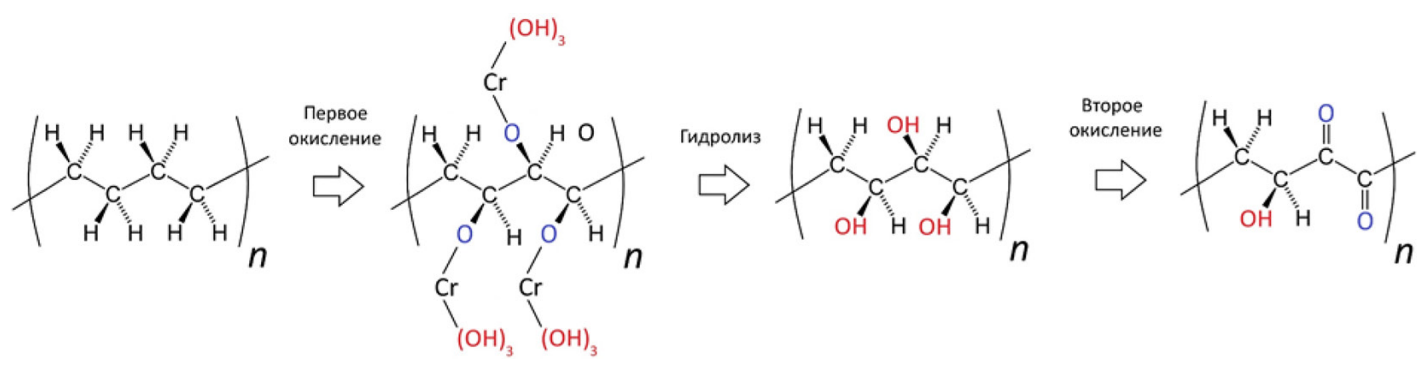

Рис. 1. Схема реакции окисления СВМПЭ раствором дихромата калия

Fig. 1. Scheme of the oxidation reaction of UHMWPE with a solution of potassium dichromate

Исследование вулканизационных характеристик резиновой смеси проведено на безроторном анализаторе перерабатываемости резин RPA 2000 фирмы Alpha Technologies (США) согласно ГОСТ Р 54547-2011. Исследование упруго-прочностных свойств при растяжении осуществлено на испытательной машине UTS-20К (Германия) согласно ГОСТ 270-75. Абразивостойкость резин оценивали по методу определения сопротивления истиранию в соответствии с ГОСТ 23509-79 на машине трения АР-40 (Россия). Твердость по Шору А и степень набухания в стандартной жидкости СЖР-3 определены согласно ГОСТ 263-75 и ГОСТ 9.030-74 соответственно. Исследование изменения свойств после термического старения на открытом воздухе и в среде СЖР-3 при $100{ }^{\circ} \mathrm{C}$ в течение 72 ч проведены согласно ГОСТ 9.024-74.

\section{Результаты и их обсуждения}

Анализ вулканизационных характеристик резиновых смесей показал (табл. 1), что введение и увеличение концентрации СВМПЭ приводит к постепенному уменьшению максимального крутящего момента $\left(S_{\text {макс }}^{\prime}\right)$ и увеличению минимального крутящего момента $\left(S_{\text {мин }}^{\prime}\right)$, что свидетельствует об увеличении вязкости резиновой смеси [17]. С увеличением содержания СВМПЭ разница между максимальным и минимальным крутящими моментами $\left(S_{\text {макс }}^{\prime}-S_{\text {мин }}^{\prime}\right)$, характеризующая густоту сшивки в резине [18, 19], уменьшается. Обнаружено, что по сравнению с образцами, содержащими исходный СВМПЭ, у образцов с травленным СВМПЭ, показатель густоты сшивки ниже. Уменьшение показателя густоты сшивки при введении СВМПЭ

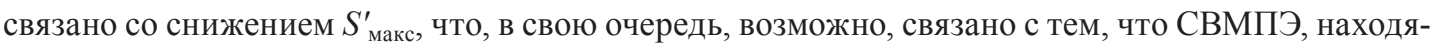
щийся в виде микрообъемов в резиновой смеси, локально препятствует (экранирует) процесс сшивки макромолекул каучука через серные мостики. Травление СВМПЭ привело к уменьшению густоты сшивки образцов на 11-14 \% по сравнению с образцами с исходным СВМПЭ.

При введении СВМПЭ и увеличении его содержания в эластомерной матрице наблюдается увеличение времени начала $\left(T_{5}\right)$ подвулканизации и времени достижения оптимума вулканизации $\left(\mathrm{T}_{90}\right)$. Существенного влияния травления СВМПЭ на изменение времени подвулканизации не обнаружено. Наблюдаемые изменения не превышают 6 \%. Однако обнаружено, что травление СВМПЭ существенно увеличивает время достижения оптимума вулканизации. Увеличение времени достижения оптимума вулканизации при введении травленного СВМПЭ, возможно, связано с тем, что вследствие увеличения химической активности СВМПЭ начинает вступать во взаимодействие не только с макромолекулами каучука через разрушение двой-

$$
-427 \text { - }
$$


Таблица 1. Вулканизационные характеристики БНКС-18АМН, наполненного СВМПЭ

Table 1. Vulcanization characteristics of UHMWPE filled BNRS-18AMN

\begin{tabular}{|c|c|c|c|c|c|c|c|c|c|c|c|}
\hline \multirow{3}{*}{ № } & \multirow{3}{*}{ Свойства } & \multicolumn{10}{|c|}{ Содержание СВМПЭ в БНКС-18АМН (в мас. ч.) } \\
\hline & & \multirow{2}{*}{0} & 5 & 10 & 15 & 5 & 10 & 15 & 5 & 10 & 15 \\
\hline & & & \multicolumn{3}{|c|}{ Исходный } & \multicolumn{3}{|c|}{3 ч травл. } & \multicolumn{3}{|c|}{20 ч травл. } \\
\hline 1 & $\mathrm{~S}_{\text {макс, }}^{\prime}$ дН·м & 27,57 & 27,04 & 25,32 & 24,79 & 24,31 & 23,25 & 22,33 & 25,02 & 24,04 & 23,29 \\
\hline 2 & $\mathrm{~S}_{\text {мин }}^{\prime}$, дН·м & 2,37 & 2,47 & 2,63 & 2,70 & 2,51 & 2,61 & 2,76 & 2,46 & 2,64 & 2,81 \\
\hline 3 & $\mathrm{~S}_{\text {макс }}^{\prime}-\mathrm{S}_{\text {мин }}^{\prime}$, дН·м & 25,20 & 24,57 & 22,69 & 22,09 & 21,80 & 20,64 & 19,57 & 22,56 & 21,40 & 20,48 \\
\hline 4 & $\mathrm{~T}_{5}$, мин & 4,31 & 4,56 & 4,88 & 4,86 & 4,61 & 4,48 & 4,28 & 4,83 & 4,88 & 4,80 \\
\hline 5 & $\mathrm{~T}_{90}$, мин & 13,90 & 14,58 & 16,03 & 15,80 & 18,58 & 20,44 & 21,51 & 17,88 & 19,24 & 20,14 \\
\hline 6 & $\mathrm{R}_{\mathrm{V}}$, мин $^{-1}$ & 10,4 & 12,9 & 11,7 & 11,9 & 8,9 & 7,5 & 6,9 & 9,7 & 8,7 & 8,0 \\
\hline
\end{tabular}

ной связи, но и с серой, что можно отнести к конкурирующему к сшивке резины через серные мостики процессу. Увеличение времени достижения оптимума вулканизации в случае использования травленного СВМПЭ отражается на показателе скорости вулканизации $R_{V}$, который рассчитывается по формуле:

$$
R_{v}=\frac{100}{T_{90}-T_{5}},\left(\text { мин }^{-1}\right)
$$

По сравнению с образцами с исходным СВМПЭ у образцов с травленным СВМПЭ $R_{V}-$ ниже.

Для всех образцов увеличение содержания СВМПЭ приводит к понижению прочности при растяжении $\left(f_{p}\right)$ и относительному удлинению при разрыве $\left(\varepsilon_{p}\right)$, но при этом повышает модуль при $100 \%$-ном удлинении $\left(f_{100}\right)$, что свидетельствует об увеличении жесткости резины (табл. 2). Травление СВМПЭ в течение 3 ч привело к уменьшению прочности при растяжении на 24, 20 и $15 \%$ и модуля при 100\%-ном удлинении на 33, 31 и $25 \%$ для образцов с 5, 10 и 15 мас. ч. СВМПЭ соответственно. При этом относительное удлинение при разрыве остается практически неизменным. Одной из причин снижения прочности при растяжении может быть уменьшение густоты сшивки в резине при введении СВМПЭ, которое было зафиксировано при определении вулканизационных характеристик. Травление СВМПЭ в течение 20 ч привело к уменьшению прочности при растяжении на 3,7 и $12 \%$ и модуля при $100 \%$-ном удлинении на 18,20 и $32 \%$ для образцов с 5, 10 и 15 мас. ч. СВМПЭ соответственно. В отличие от образцов резин с травлением СВМПЭ в течение 3 ч наблюдается обратная картина, т. е. с увеличением содержания травленного в течение 20 ч СВМПЭ разница между прочностными характеристиками между образцами с исходным и травленным СВМПЭ увеличивается. Причем у всех образцов с травленным в течение 20 ч СВМПЭ относительное удлинение при разрыве выше по сравнению со всеми исследованными образцами, включая исходную резину. Существенного влияния введения СВМПЭ, а также его травления на коэффициент морозостойкости БНКС-18АМН при минус $40{ }^{\circ} \mathrm{C}\left(\mathrm{K}_{\mathrm{M}}\right.$, минус $\left.40^{\circ} \mathrm{C}\right)$ не обнаружено.

Каждое увеличение содержания СВМПЭ в БНКС-18АМН на 5 мас. ч. увеличивает твердость на 1 усл. ед. По сравнению с образцами, содержащими исходный СВМПЭ, образцы с травленным СВМПЭ менее твердые. Увеличение продолжительности травления приводит 
Таблица 2. Свойства образцов БНКС-18АМН, наполненных СВМПЭ

Table 2. Properties of the samples of UHMWPE filled BNRS-18AMN

\begin{tabular}{|c|c|c|c|c|c|c|c|c|c|c|c|}
\hline \multirow{3}{*}{ № } & \multirow{3}{*}{ Свойства } & \multicolumn{10}{|c|}{ Содержание СВМПЭ в БНКС-18АМН (в мас. ч.) } \\
\hline & & \multirow{2}{*}{0} & 5 & 10 & 15 & 5 & 10 & 15 & 5 & 10 & 15 \\
\hline & & & \multicolumn{3}{|c|}{ Исходный } & \multicolumn{3}{|c|}{3 ч травл. } & \multicolumn{3}{|c|}{20 ч травл. } \\
\hline 1 & $\mathrm{f}_{\mathrm{p}}, \mathrm{M \Pi а}$ & 13,2 & 12,6 & 11,1 & 9,8 & 9,5 & 8,9 & 8,3 & 12,2 & 10,3 & 8,6 \\
\hline 2 & $\mathrm{f}_{100}, \mathrm{M \Pi а}$ & 2,6 & 2,7 & 2,9 & 3,1 & 1,8 & 2,0 & 2,3 & 2,2 & 2,3 & 2,1 \\
\hline 3 & $\varepsilon_{\mathrm{p}}, \%$ & 517 & 500 & 480 & 440 & 500 & 480 & 480 & 550 & 520 & 500 \\
\hline 4 & $\mathrm{~K}_{\mathrm{M}},-40^{\circ} \mathrm{C}$ & 0,17 & 0,19 & 0,20 & 0,22 & 0,17 & 0,18 & 0,17 & 0,18 & 0,17 & 0,18 \\
\hline 5 & Твердость, Шор А & 58 & 61 & 62 & 63 & 58 & 59 & 60 & 59 & 60 & 61 \\
\hline 6 & Набухание, \% & 29,3 & 28,5 & 28,0 & 28,6 & 30,0 & 29,6 & 29,9 & 29,9 & 30,0 & 30,5 \\
\hline \multicolumn{12}{|c|}{ После старения на воздухе при $100^{\circ} \mathrm{C}$ в теч. 72 ч } \\
\hline 1 & $f_{p}, \%$ & +15 & +9 & +12 & +15 & +17 & +19 & +32 & +41 & +40 & +35 \\
\hline 2 & $\varepsilon_{\mathrm{p}}, \%$ & -34 & -24 & -22 & -25 & -41 & -39 & -37 & -34 & -39 & -45 \\
\hline 3 & Твердость, Шор А & +4 & +3 & +3 & +4 & +4 & +5 & +6 & +8 & +6 & +7 \\
\hline \multicolumn{12}{|c|}{ После старения в СЖР-3 при $100{ }^{\circ} \mathrm{C}$ в теч. 72 ч } \\
\hline 1 & $f_{p}, \%$ & -13 & -9 & -13 & -14 & +11 & +1 & -17 & -13 & -6 & +0 \\
\hline 2 & $\varepsilon_{\mathrm{p}}, \%$ & -6 & -5 & -11 & -10 & -10 & -16 & -14 & -18 & -16 & -16 \\
\hline 3 & Твердость, Шор А & -17 & -18 & -17 & -16 & -12 & -15 & -15 & -17 & -17 & -17 \\
\hline
\end{tabular}

к небольшому увеличению твердости образцов. По сравнению с резинами, содержащими СВМПЭ, травленного в течение 3 ч, у резин с СВМПЭ, травленного в течение 20 ч, твердость на 1 усл. ед. выше.

Существенного влияния СВМПЭ на набухание образцов при температуре $100{ }^{\circ} \mathrm{C}$ в течение 72 ч в СЖР-3 не обнаружено. Все исследованные образцы набухают примерно на 28-30 \%, с разбросом $\pm 2 \%$. У образцов с травленным СВМПЭ, по сравнению с образцами с исходным СВМПЭ, наблюдается небольшое увеличение набухания (на 1-2 \%), что в большей степени связано с уменьшением густоты сшивки в резине.

Исследование потери физико-механических свойств и твердости образцов резин после старения на открытом воздухе показало, что при введении исходного СВМПЭ признаки термоокислительной деструкции проявляются меньше. В частности, уменьшается изменение прочности при растяжении $\left(f_{p}, \%\right)$, относительного удлинения при разрыве $\left(\varepsilon_{p}, \%\right)$ и твердости по Шору А $(\Delta \mathrm{H})$. Однако установлено, что травление СВМПЭ приводит к заметному ухудшению стойкости к тепловому старению в условиях доступа кислорода воздуха. Наибольшему изменению подвергается прочность при растяжении. Так, например, у образцов, содержащих 5 мас. ч. СВМПЭ, травленного в течение 20 ч, разница в прочности при растяжении по сравнению с ненаполненной резиной и резиной, наполненной 5 мас. ч. исходным СВМПЭ, составляет 25,9 и 31,8 МПа соответственно. Ухудшение термической стойкости в условиях доступа кислорода, возможно, объясняется тем, что кислородсодержащие группы, которые образовываются при окислении СВМПЭ, в условиях длительного термического воздействия способствуют дополнительной сшивке резины, что приводит к увеличению ее прочности и охрупчиванию. 


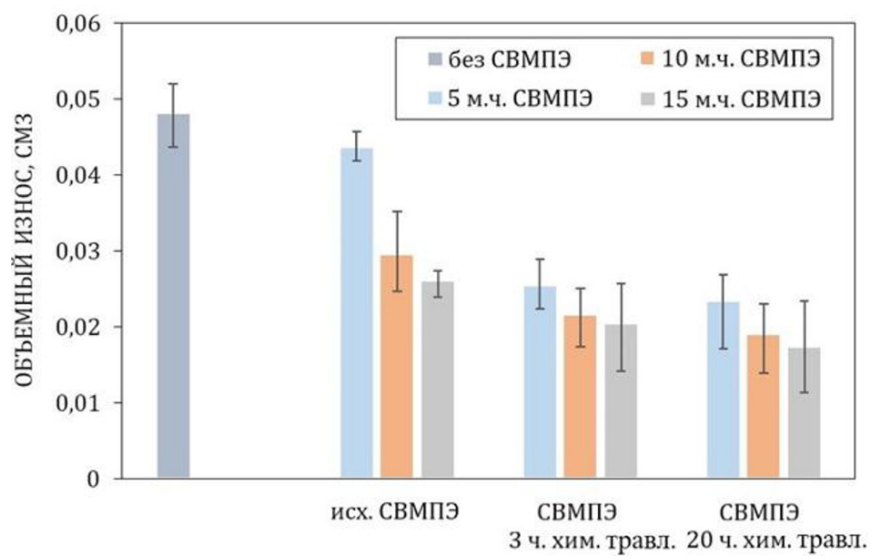

Рис. 2. Объемный износ образцов БНКС-18АМН, наполненных СВМПЭ

Fig. 2. Bulk wear of the samples of UHMWPE filled BNRS-18AMN

В отличие от старения в условиях открытого доступа кислорода воздуха при старении в среде СЖР-3 при температуре $100{ }^{\circ} \mathrm{C}$ в течение 72 ч вследствие проникновения молекул жидкости в резину наблюдается уменьшение прочности при растяжении $\left(f_{p}, \%\right)$ и твердости образцов $(\Delta \mathrm{H})$. Влияние травления СВМПЭ на стойкость к термическому старению в углеводородной среде не обнаружено. Наблюдается увеличение разброса показателей изменения физико-механических свойств, что, видимо, связано с неравномерностью распределения химической модификации СВМПЭ.

Исследование стойкости образцов к абразивному истиранию показало, что введение СВМПЭ и увеличение его содержания приводят к уменьшению объемного износа, т. е. к повышению стойкости к абразивному истиранию (рис. 2). Образцы с травленным СВМПЭ по сравнению с образцами с исходным СВМПЭ более износостойкие. Существенных отличий между образцами с продолжительностью травления СВМПЭ в течение 3 и 20 ч не наблюдается. Однако все же у образцов с травлением в течение 20 ч объемный износ на 8-15\% меньше по сравнению с образцами с травлением в течение 3 ч.

\section{Заключение}

Химическое травление СВМПЭ может быть использовано как способ воздействия на реологические и вулканизационные свойства эластомерных композитов на основе БНКС-18АМН, наполненных СВМПЭ. В частности, химическое травление СВМПЭ приводит к уменьшению вязкости резиновой смеси, уменьшению скорости вулканизации и увеличению времени достижения оптимума вулканизации, а также уменьшению плотности образования трехмерной пространственной структуры в резине.

Прочностные показатели резины на основе БНКС-18АМН при введении травленного СВМПЭ снижаются, но при этом увеличивается стойкость к абразивному истиранию. Травление СВМПЭ негативно влияет на стойкость к термическому старению в условиях доступа кислорода воздуха, а на набухание и сохранение свойств после термического воздействия в углеводородной среде существенного влияния не имеет. 


\section{Список литературы / References}

[1] Папков В.Н., Гусев Ю.К., Ривин Э.М., Блинов Е. В. Бутадиен-нитрильныле каучуки. Синтез и свойства, Воронеж: ВГУИТ, 2014, 218 с. [Papkov V.N., Gusev Yu.K., Rivin E.M., Blinov E. V. Nitrile butadiene rubbers. Synthesis and properties, Voronezh, VGUIT, 2014, 218 p. (in Russian)].

[2] Mammadov S.M., Rzayeva S.A., Garibov A.A., Akperov O.N., Gojayeva T.F., Mammadov J. S., Hajiyeva N. M. Study of Influence of Copolymer Vinyl Chloride and Vinyl Acetate on the Properties of Butadiene Nitrile Rubber, International Journal of Composite Materials, 2012, 2(6), p. 137-141. DOI: 10.5923/j.cmaterials.20120206.04.

[3] Zhang J., Zhang H., Chen F., Liu M. Improving Stability of Mechanical Properties for Nitrile Butadiene Rubber Composite by Carbon Nanotube with Antioxidant Loading Distribution, Polymer Composites, 2018, 40(52), E1172-1180, DOI: 10.1002/pc.24929.

[4] Вишневский К.В., Шашок Ж.С. Использование высокодисперсной углеродной добавки в эластомерных композициях на основе каучуков различного назначения, Tpyды БГТУ, 2012, 4, 56-60. [Vishnevsky K. V., Shashok Zh.S. Use of a highly dispersed carbon additive in elastomeric compositions based on rubbers for various purposes, Proceedings of BSTU, 2012, 4, 56-60 (in Russian)].

[5] Шашок Ж.С., Усс Е.П., Кротова О.А., Круглик Н.В. Свойства эластомерных композиций с волокнистыми модифицирующими добавками, Труды БГТУ, 2018, серия 2, 1, 86-91. [Shashok Zh.S., Uss E.P., Krotova O.A., Kruglik N.V. Properties of elastomeric compositions with fibrous modifying additives, Proceedings of BSTU, 2018, Series 2, 1, 86-91 (in Russian)].

[6] Юловская В.Д., Монахова Т.М., Петрова В.С., Карпова С. Г. Влияние состава резиновой смеси на стойкость к старению вулканизатов на основе бутадиен-нитрильных каучуков разной полярности, Каучук и резина, 2017, 76(1), 32-34. [Yulovskaya V.D., Monakhova T.M., Petrova V.S., Karpova S.G. The influence of the composition of the rubber mixture on the aging resistance of vulcanizates based on butadiene-nitrile rubbers of different polarity, Kauchuk $i$ rezina, 2017, 76(1), 32-34 (in Russian)].

[7] Шевченко Т.А., Шевченко Н. М. Повышение маслобензостойкости вулканизатов на основе нитрильного каучука, Каучук и резина, 2000, 5, 19-22. [Shevchenko T.A., Shevchenko N. M. Increasing the oil and petrol resistance of vulcanizates based on nitrile rubber, Kauchuk i rezina, 2000, 5, 19-22 (in Russian)].

[8] Слободкина К.Н., Макаров Т.В., Сираева Р.Ф., Вольфсон С. И. Особенности вулканизации и упруго-прочностные свойства композиций на основе смеси бутадиен-нитрильного каучука и тиокола, Вестник Казанского технологического университета, 2011, 14, 114-118. [Slobodkina K. N., Makarov T.V., Siraeva R.F., Wolfson S. I. Features of vulcanization and elasticstrength properties of compositions based on a mixture of butadiene-nitrile rubber and Thiokol, Bulletin of the Kazan Technological University, 2011, 14, 114-118 (in Russian)].

[9] Ливанова Н.М., Попов А.А. Внутри- и межфазное сшивание в композитах бутадиеннитрильных каучуков с поливинилхлоридом и их озоностойкость, Химическая физика, 2019, 38(3), 64-69. [Livanova N.M., Popov A.A. Intra- and interfacial crosslinking in composites of butadiene-nitrile rubbers with polyvinyl chloride and their ozone resistance, Chemical Physics, 2019, 38(3), 64-69. DOI: 10.1134/S0207401X19020109 (in Russian)]. 
[10] Вольфсон С.И., Охотина Н. А., Нигматуллина А.И., Сабиров Р.К. Исследование упругогистерезисных характеристик динамических термоэластопластов, Вестник Казанского технологического университета, 2012, 15(11), 100-101. [Wolfson C.I., Okhotina N.A., Nigmatullina A. I., Sabirov R.K. Investigation of elastic-hysteresis characteristics of dynamic thermoplastic elastomers, Bulletin of the Kazan Technological University, 2012, 15(11), 100-101 (in Russian)].

[11] Заикин А.Е., Бобров Г.Б. Влияние содержания акрилонитрила в бутадиен-нитрильном каучуке на свойства динамических термоэластопластов на его основе, Вестник Казанского технологического университета, 2014, 17(16), 105-109. [Zaikin A.E., Bobrov G.B. The effect of acrylonitrile content in nitrile butadiene rubber on the properties of dynamic thermoplastic elastomers based on it, Bulletin of the Kazan Technological University, 2014, 17(16), 105-109 (in Russian)].

[12] Shadrinov N.V., Sokolova M. D., Okhlopkova A. A., Lee Jungkeun, Jeong Dae-Yong, Shim Ee Le, Cho Jin-Ho. Enhancement of Compatibility Between Ultrahigh-Molecular-Weight Polyethylene Particles and Butadiene-Nitrile Rubber Matrix with Nanoscale Ceramic Particles and Characterization of Evolving Layer, Bulletin of the Korean Chemical Society, 2013, 34(12), 3762-3766. DOI:10.5012/ bkcs.2013.34.12.3762.

[13]Шадринов Н.В., Соколова М.Д., Давыдова М. Л. Разработка морозостойких эластомерных композитов, опытно-промышленные испытания и внедрение в промышленность Республики Саха (Якутия), Горный информационно-аналитический бюллетень (научно-технический журнал), 2017, S24, 319-328. [Shadrinov N.V., Sokolova M.D., Davydova M.L. Development of frost-resistant elastomeric composites, experimental-industrial tests and introduction into the industry of the Republic of Sakha (Yakutia), Mining information and analytical bulletin (scientific and technical journal), 2017, S24, 319-328. DOI: 10.25018/0236-1493-2017-11-24-319-328 (in Russian)].

[14]Соколова М.Д., Давыдова М. Л., Шадринов Н.В. Модифицирование поверхности дисперсных наполнителей для их использования в полимерэластомерных композитах, Физикохимия поверхности и защита материалов, 2018, 54(5), 1-9. [Sokolova M.D., Davydova M.L., Shadrinov N. V. Modification of the surface of dispersed fillers for their use in polymer-elastomeric composites, Physical chemistry of surfaces and protection of materials, 2018, 54(5), 1-9. DOI: 10.1134/ S0044185618050315 (in Russian)].

[15]Li W., Meng L., Wang L., Mu J., Pan Q. Surface modification of ultra-high molecular weight polyethylene fibers by chromic acid. Surf. Interface Anal., 2016, 48, 1316-1319. DOI: 10.1002/sia.6040.

[16]Silverstein M.S., Breuer O. Relationship between surface properties and adhesion for etched ultra-high-molecular-weight polyethylene fibers, Composites Science and Technology, 1993, 48(1-4), 151-157. ISSN0266-3538, https://doi.org/10.1016/0266-3538(93)90131-Y.

[17] Yahaya L.E., Adebowale K.O., Olu-Owolabi B.I. Cure Characteristics and Rheological Properties of Modified Kaolin-natural Rubber Composites, American Chemical Science Journal, 2014, 4(4), 472-480. DOI:10.9734/ACSJ/2014/6575.

[18]Honorato L., Lopes Dias M., Azuma C., Reis Nunes R.C. Rheological properties and curing features of natural rubber compositions filled with fluoromica ME100, Polimeros, 2016, 26(3), 249253. DOI:10.1590/0104-1428.2352.

[19]Lopez-Manchado M.A., Arroyo M. A., Herrero M. B., Biagiotti J. Vulcanization kinetics of natural rubber-organoclay nanocomposites, Journal of Applied Polymer Science, 2003, 89(1), 1-15. DOI:10.1002/app.12082. 